\title{
Modification of Combined Vibrated Power Assisted Liposuction with Periareolar Gland Excision in management of Gynecomastia
}

\author{
Kurdo Akram Qradaghi*, Ismael Hassan Berzenji ${ }^{* *}$, Dana Abdimagid Abdilkarim*, Ari Raheem Zangana ***
}

\section{ABSTRACT 2016. \\ $\mathrm{G}$}

Background: The recognized procedures that have been used to treat gynecomastia are said to have relatively a long operative time, less patient satisfaction rate, they are merely used, in mild to moderate gynecomastia, leaves a mild bulging over the nipple areola complex, resulting in aesthetically unsatisfactory results. The more the grade of gynecomastia, the more complicated the used surgical techniques. This study evaluates the success rate of these simplest surgical technique in higher grades of gynecomastia.

Objectives: to present the experiences with use of Modification of Combined Vibrated Power Assisted Liposuction with Periareolar Gland Excision in management of in different type Gynecomastia

Type of the study: This is a retrospective study

Methods: The study includes the use of a modification of combine vibrated power-assisted liposuction with periareolar gland excision applied for managing different types of gynecomastia. In 23 consecutive patients (46 breasts) treated between February of 2011 and March of

Results: 23 patients (46 breasts) were successfully treated using this technique. Volume aspirated in both breast was
$792 \mathrm{ml}$ (range, 450 to $1600 \mathrm{ml}$ ). Using the periareolar excision technique, the mean operative time was 55 minutes (range, 45 to 90 minute). Complications were minimal (1.5\% per breasts), and no revisions were required. Conclusions: The modified Combined vibrated power assisted liposuction and the periareolartechnique have demonstrated to be a less time consuming versatileapproach, for the treatment of gynecomastia and consistently produces a smoothcontoured male breast, it is promising method to achieve good aesthetic results in gynecomastia surgerywhile resulting in an inconspicuous scar.

Key words: gynecomastia, liposuction,periareolar gland excision

\section{Al-Kindy College Medical Journal 2018: Vol. 14 No.1} Page: $18-23$

*Assisted Professor plasticsurgeon, Duhok. Iraq

${ }^{* *}$ F.I.C.M.S plastic surgeon, Erbil. IRAQ

${ }^{* * *}$ Assisted Professor plastic surgeon, Sulaimany, Iraq

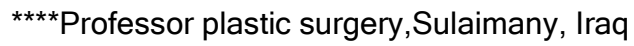

Received $3^{\text {th }}$ Nov 2016, accepted in final $4^{\text {th }}$ Jan 2018

Corresponding to: KurdoAkram, e - mail: kurdoqradaghi@gmail.com, mobile: 07507964440 ynecomastia is regarded as the most common benign condition in male ${ }^{(1,2)}$. It is occurring in 2/3rd of male adolescent ${ }^{(3)}$, About quarter of patients have idiopathic gynecomastia and twenty-five percent have acute or persistent gynecomastia due to puberty. Gynecomastia causes include medication, chronic liver diseases or malnourishment primary hypogonadism, testicular tumors, secondary hypogonadism, hyperthyroidism, and kidney disease ${ }^{(4)}$. Gynecomastia is result from a disproportion between Estrogens, which stimulate the development of mammary tissue, and Testosterone, which antagonize this effect. $(5,6)$. Inpatient with (idiopathic)type,if more than one-yearhas passed without regression of size, surgery may be indicated, Secondary etiology should be solved before surgical interference $(6,7)$ Simon and his colleague classified gynecomastia into 4 grades: grade 1: small enlargement, no skin excess; grade 2a: moderate enlargement, no skin excess; grade 2b: moderate enlargement with extra skin; grade 3: marked enlargement with extra skin. $\left.{ }_{1}, 2 .{ }^{7}\right)$ The aim of gynecomastia surgery is to restore a normal chest contour with minimal signs of breast surgery. Surgical modalities include a variety of incisions, excisions, suction-assisted lipectomy, power assisted liposuction, ultrasound-assisted liposuction, or some combination of these methods. (9). The combination of liposuction and min incision gland technique is more prevalent. (10) However, there may be sequelae and complications such as being a time-consuming procedure, being used in only in Simon I and II classifications, under-correction, skin remnant, a bulging gland disc or dish gland appearance, insertion of drain, and seroma formation (10) The aim of the study: To overcome these disadvantages a lot of modification have been done to make this procedure become a more versatile, use the simplest surgical technique in higher grades of gynecology, less time consuming with lest complications.

Method: This is a retrospective study of 23 consecutive patients (46 breasts ), idiopathic type gynecomastia, with more than several years operated, Between February 2011 and March 2016, underwent modification in gynecomastia liposuction by vibrated power assisted liposuction and peri areolar gland excision in Duhok, Howler and Sulaimany plastic surgery hospitals, all patients were at young age group, these were from 17 to 42 (mean age 32), All the patients underwent a clinical and hormonal screening for physiological, pharmacological and various pathological causes, All the cases included in the study were of idiopathic etiology, All the subjects sought medical help for cosmetic reasons. Patients were seen by the authors on postoperative day 5,14 days postoperatively, 1 month postoperatively, and at 12 weeks postoperatively. The following data were collected: age, size of the breast, consistency, skin excess, present of ptosis, skin qualities, development of inframammary fold (IMF), 
volume aspirated per breast using power-assisted liposuction, amount of tissue excised per breast using the pull-through technique, operative time, and the number of complications. The follow-up ranged from 1 year to 2 years, and the results were evaluated by the same person who had also performed the surgery.Preoperative Evaluation: Use careful palpation and the pinch test, noting the degree of sagging and the elasticity of the tissues to determine the size and thickness of the fibrous gynecomastia and the surrounding fat. patients must stop aspirin, ibuprofen, alcohol, vitamin E, and tobacco for 10 days before surgery. also, enquire patients to wash a surgical soap before surgery.

\section{Operative Technique}

Skin Marking: (figures 1,2,3,4,5) After taking front, oblique and lateral photography. Chest midline, inframammary, periareolar outline of breast with site of liposuction below inframammary line are marked in standing position. The area of liposuction is topographically marked. Operation done under general anesthesia. Each breast is infiltrated Tumescent fluid contains $500 \mathrm{ml}$ of a solution made of $1000 \mathrm{ml}$ Ringer's lactate solution mixed with $20 \mathrm{ml}$ of 2 percent lidocaine and $1 \mathrm{ml}$ of 1:1000 epinephrine. Via $4 \mathrm{~mm}$ vibrated PAL liposuction machine in different direction.

Power-Assisted Liposuction for Removal of Breast Tissue (Figure 1): The liposuction is started first, powerassisted liposuction is used to reduce breast volume arising mainly from fat. The preference to use vibrated 4 $\mathrm{mm}$ power-assisted liposuction because it helps in passing the liposuction cannula both through the fibrous parenchymal framework of the breast and at the same time it aids the scatter of tumescent fluid into exact fat tissue that needs to be removed. Liposuction of the whole breast is first made in the intermediate layer of the subcutaneous fatty layer. Subsequent, consideration is focused on the breast tissue situated deep to the nippleareola complex. Liposuction of this region is done at the subdermal level, which we believe that it enhances skin contraction in the postoperative period.

The periareolar Technique for Excision of Fibro Glandular Breast Tissue: Figure 2, Figure 3, figure 4 and figure 5 Through periareolar incision, total mammary gland was excised totally via electrical cautery, leaving behind about $1 \mathrm{~cm}$ thick flap, without jeopardizing the pectoralis fascia.The nipple areolar beneath disc have undergonedebulking by fine scissor and then undergo waffle like cutting under surface, this maneuver is to prevent postoperative bulging at site of nipple areolar complex and make the nipple spread softly attach to pectoralis fascia. Thus, prevent dishing like appearance postoperatively

Breast Tissue Contouring via Power-Assisted Liposuction: Vibrated power-assisted liposuction is necessary, for finishing contouring and to prevent irregularities in the remaining breast tissue and to soften the breast contour and blend the nipple-areola complex with the surrounding breast tissue. The flap underwent quilting sutures through $6,9,12$ and 3 o'clock, by 4 vicryl sutures. This prevents seroma formation and decrease empty space, shear force and help faster contraction of the extra skin and faster postoperative appearance, no any drain needed to be inserted. The periareolar incision suture by 2-layer inner $4 / 0$ vcryl suturing, the two-inner edge with deep fascia of pectoralis and outer sub cuticle running suture by $4 / 0$ proline, no suture to the liposuction incision as to allow leaking of bloody fluid which may persist for 24 hours the wounds are dressed in dry gauze, and a pressure garment is applied to the chest wall.

Postoperative Management: The patient must wear a pressure garment day and night for a total of 12 weeks and night time for 3 to 6 the months to allow the skin of the breast to adhere to the underlying tissues. Patients may return to their normal level of activity 3 weeks postoperatively Postoperatively advice patient to applied garment dressing and message for 3 to 4 months, and seen the patient on day 5,14 and every 3 to 6 months

Results:(Tabe1), Figure (7), Figure (8) and Figure (9) The technique of modified combining power-assisted liposuction and the periareolar total gland excision has been used in twenty-three patients with bilateral idiopathic gynecomastia with various degrees of Gynecomastia. Aged 17 to 42 (mean=28) were treated. The average volume of fat aspirated in both breast was $792 \mathrm{ml}$ (range, 450 to $1600 \mathrm{ml}$ ). The average operative time was 55 minute (range, 45 to 90 minute) None of the 28 patients reported any alteration of sensation in the nipple-areola region after 6 months. All had diffuse breast enlargement without discrete, hard sub areolar lumps. The sizes were recorded as small, medium, or large, and consistency as soft, moderate, or firm. There was no preponderance of any one characteristic (Table I). Swelling and skin tethering are main immediate postoperative observation, two patients developed hematoma, one in right and other in the left side, and one patient developed excess skin in both breast and 1 patient $(2.2 \%)$ was slightly undercorrected on one side and underwent new surgical gland excision and secondary liposuction to improve the result. We observed no other complications (irregularities, hypopigmentation, infections, seromas), and after 1 to 3 years follow up were good and natural.

Discussion :Surgical treatment remains the main solution for long standinggynecomastia ${ }^{(11}$ and 12$)$. There are different surgical modalities for treating gynecomastia, the liposuction and gland excision are the more famous among them. (11 and 12 ). Combined suction assisted liposuction and Periareolar gland excision was first described by Morselli ${ }^{(11)}$ at 1996 , He used this method in eleven patients with great success, using ultrasound assisted liposuction together with gland pull through described by Hamond el at ${ }^{(12)}$ using single incision site, but many complications like seroma and burn, at the site of suction were found. Frank and Jamil Ahmad ${ }^{(13)}$ used combined electrical assisted liposuction and pull through gland excision in ninety-six patients managed with this procedure were satisfied with their results. Using this modification technique Since February 2011, we have effectively managed 23 consecutive patients, most of them satisfied with their result except four of them due to present of minor complications( hematoma, skin excess), in one of 
patient had under correction necessitate secondary liposuction and periareolar excision, and we believe that this procedure has been recognized to be versatile in treating various degrees of gynecomastia for several reasons; first, the use of vibrated electrical liposuction is safe, less time consuming for tumescent fluid installation in adipose tissue through the dense parenchymal framework and at same time aspiration which needs less surgeon effort, fatigue and less operative time by half hour without waiting for of adrenalin time to work. The possibility of liposuction complications became minima like (under the section, displaced epithelium, protruded or dish appearance, nipple-areolar complex) ${ }^{(14)}$ by adding peri-areolar gland excision which leaves a universe texture as maintain normal contour of the chest and the breast and leave no more scars. Many studies use the liposuction and gland excision in Simon I and II (15 and 16) but in this case study, we usedit in all types of gynecomastia. The postoperative garment is very important epically for Simon II and III as it makes a faster healing. The nipple areolar complex defatting and waffle-like cutting allow the nipple areolar complex to optimize the position and not lead to post appearance contraction of nipple areolar complex or bulging which most young man criticizes the surgeon about it. Quilting sutures is well known in breast reconstruction and abdominoplasty (17 and 18). Here the advantages are: closing down the open tissue plane (dead space) which prevent pocket for seroma formation, and tension outspread, sharing the tension and supporting forces via multiple sutures thus eliminated drains insertion and minimize seroma formation, we did not have single seroma case in this case series, but the bothering sequelae was a post-operative dimpling for several weeks. In this case study, there was no surgical resectingof skin excess, because the rupture of the fibrous septa which connect the skin to fat tissue, was achieved during liposuction, results in excellent skin contraction and final esthetic results.

Conclusions: Since 2011, this technique was used to successfully treat 23 percent of their gynecomastia patients. The modify Combining vibrated powerassisted liposuction and the periareolar technique has demonstrated to be a less time consuming versatile approach, for the treatment of gynecomastia and consistently produces a smooth contoured male breast promising method to achieve good aesthetic results in gynecomastia surgery while resulting in an inconspicuous scar.

Table-1- Showing data collection for the consecutive patients

\begin{tabular}{|c|c|c|c|c|c|c|c|c|}
\hline Number & Age & SIZE & CONSISTENCY & $\begin{array}{c}\text { EXCESS } \\
\text { SKIN }\end{array}$ & PTOSIS & $\begin{array}{l}\text { DEVELOPMENT } \\
\text { OF }\end{array}$ & $\begin{array}{c}\text { VOLUM } \\
\text { ASPIRATED } \\
\text { IN BOTH } \\
\text { BREAST CC }\end{array}$ & $\begin{array}{c}\text { operative } \\
\text { time in } \\
\text { minute }\end{array}$ \\
\hline patients & year & ${ }^{*} \mathrm{~L}$ & ${ }^{*} S$ & & & ${ }^{*}$ IMF & & \\
\hline & & ${ }^{*} \mathrm{M}$ & ${ }^{*} \mathrm{M}$ & & & & & \\
\hline & & ${ }^{*} S$ & ${ }^{*} \mathrm{~F}$ & & & & & \\
\hline & & & & & & & & \\
\hline 1 & 22 & M & $\mathrm{S}$ & NO & NO & NO & 1000 & 60 \\
\hline 2 & 27 & M & $\mathrm{F}$ & YES & NO & NO & 1100 & 60 \\
\hline 3 & 36 & $\mathrm{~L}$ & M & YES & YES & YES & 1600 & 75 \\
\hline 4 & 19 & $S$ & $\mathrm{~S}$ & NO & No & NO & 720 & 60 \\
\hline 5 & 35 & M & $\mathrm{F}$ & $\mathrm{NO}$ & YES & NO & 820 & 55 \\
\hline 6 & 40 & $\mathrm{~L}$ & M & YES & NO & YES & 1120 & 60 \\
\hline 7 & 25 & $\mathrm{~s}$ & $\mathrm{~s}$ & No & NO & NO & 1200 & 65 \\
\hline 8 & 21 & M & $\mathrm{F}$ & NO & YES & NO & 710 & 50 \\
\hline 9 & 38 & $\mathrm{~L}$ & $S$ & NO & NO & YES & 898 & 55 \\
\hline 10 & 22 & S & $\mathrm{F}$ & NO & NO & NO & 450 & 55 \\
\hline 11 & 17 & M & $\mathrm{M}$ & NO & YES & NO & 600 & 55 \\
\hline 12 & 42 & M & $S$ & YES & NO & NO & 740 & 60 \\
\hline 13 & 37 & M & $\mathrm{F}$ & NO & NO & NO & 840 & 60 \\
\hline 14 & 41 & $\mathrm{~L}$ & M & YES & YES & YES & 1600 & 90 \\
\hline 15 & 25 & $S$ & $\mathrm{~S}$ & NO & NO & NO & 590 & 40 \\
\hline 16 & 24 & M & M & YES & NO & NO & 640 & 50 \\
\hline 17 & 19 & $\mathrm{~L}$ & $\mathrm{~S}$ & NO & NO & NO & 540 & 40 \\
\hline 18 & 30 & $\mathrm{~L}$ & M & YES & NO & YES & 730 & 40 \\
\hline 19 & 37 & $S$ & $M$ & NO & YES & NO & 640 & 40 \\
\hline 20 & 21 & $M$ & $S$ & YES & NO & NO & 450 & 59 \\
\hline 21 & 35 & $\mathrm{~L}$ & $M$ & NO & YES & YES & 540 & 50 \\
\hline 22 & 26 & $S$ & $S$ & YES & NO & NO & 530 & 45 \\
\hline 23 & 24 & $S$ & $M$ & NO & NO & NO & 652 & 45 \\
\hline
\end{tabular}




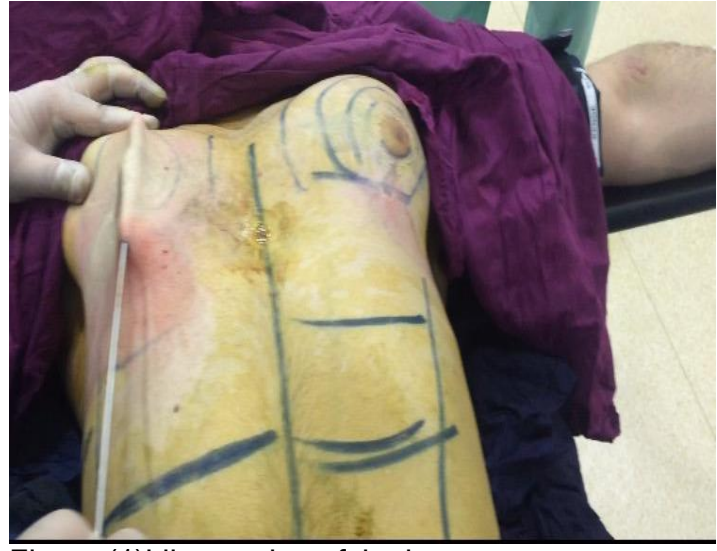

Figure (1)Lliposuction of the breas

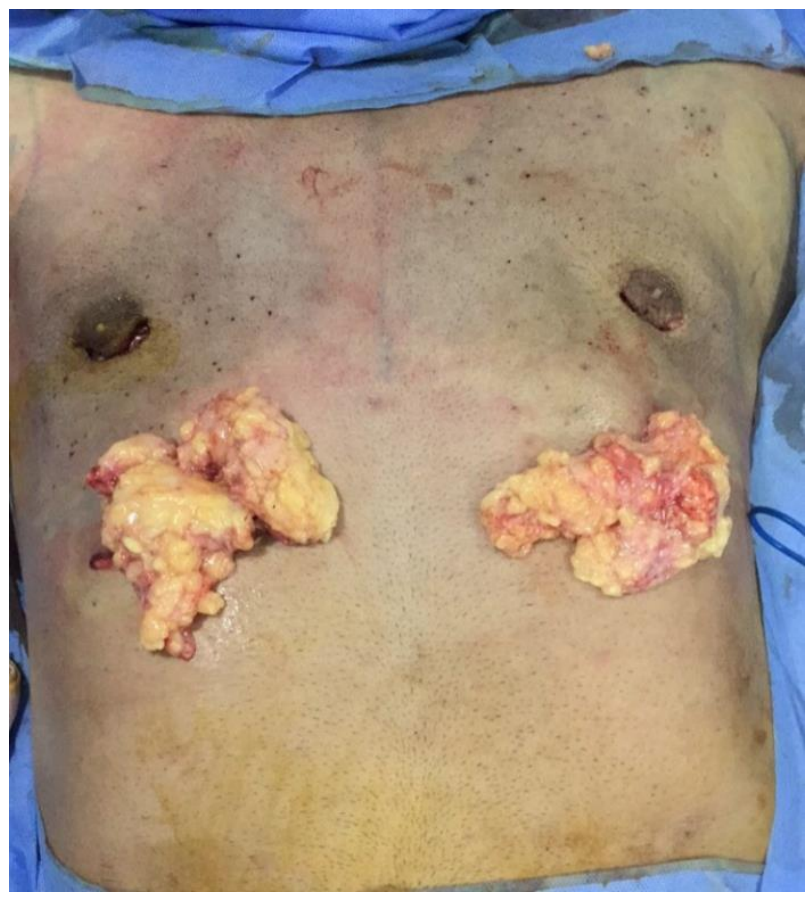

Figure (2) Periareolar approach for removal of the fibro glandular breast tissue.

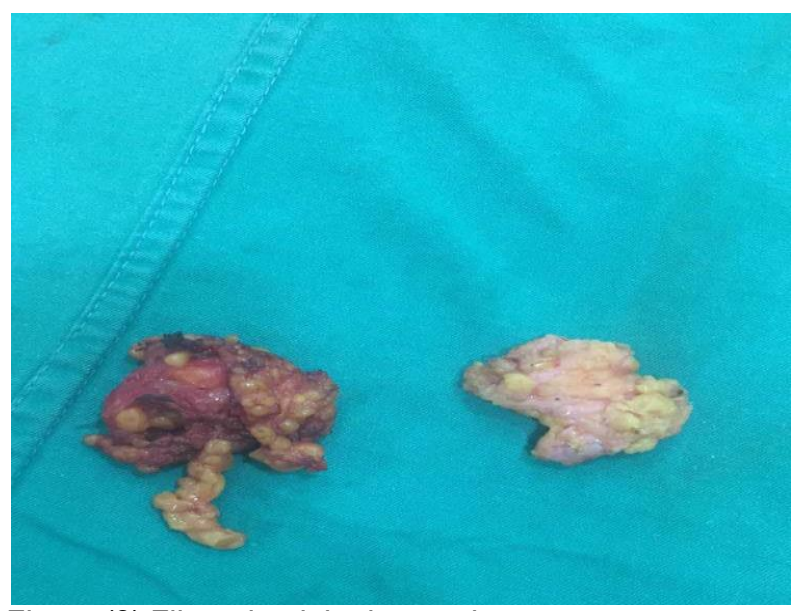

Figure (3) Fibro glandular breast tissue

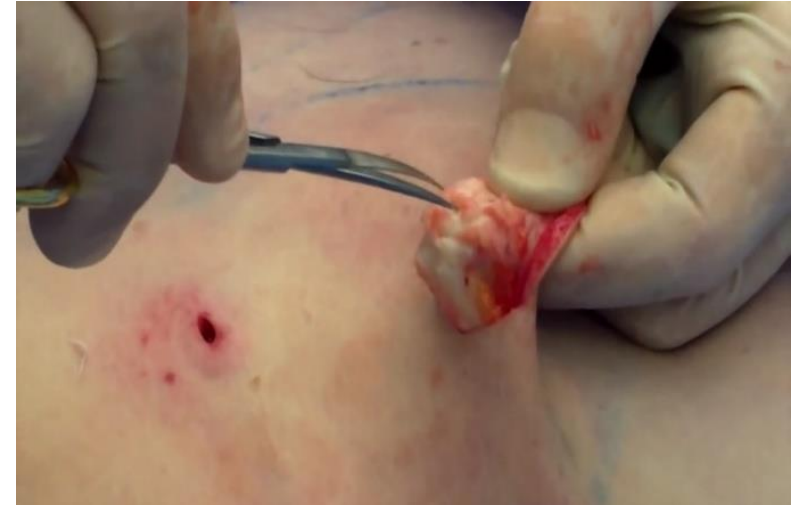

Figure (4) Debunking by fine scissor and then undergo waffle like cutting under surface.

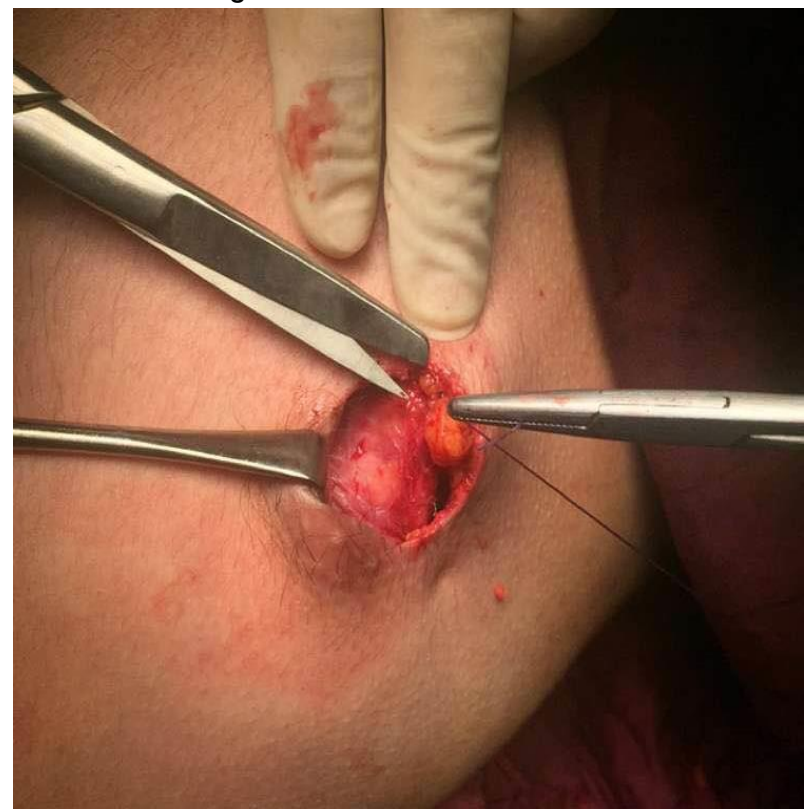

(Figure 5) Quilting suture between skin flap and derlying fascia

Figure 6 (a \&b) Simon 3 Gynecomastia preoperative marking and the post-operative result
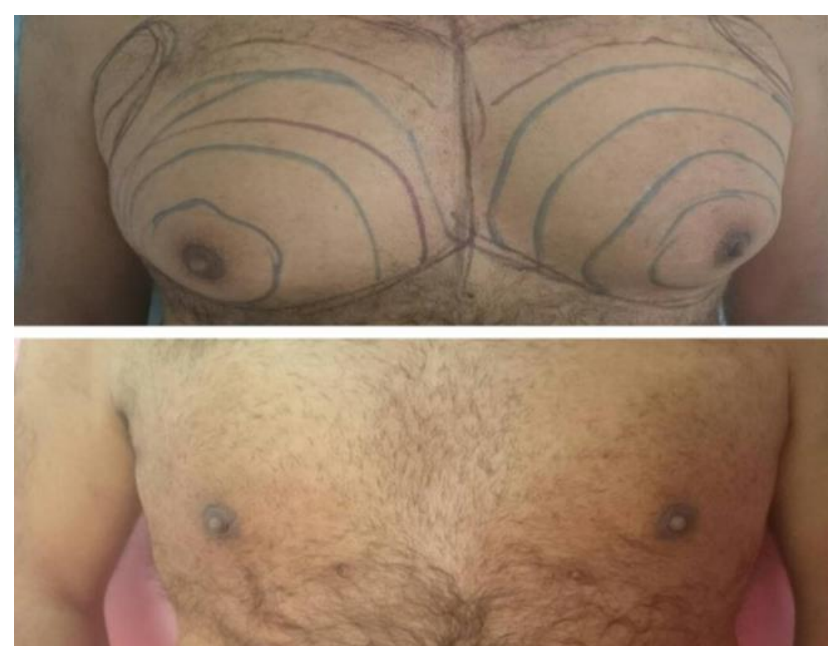


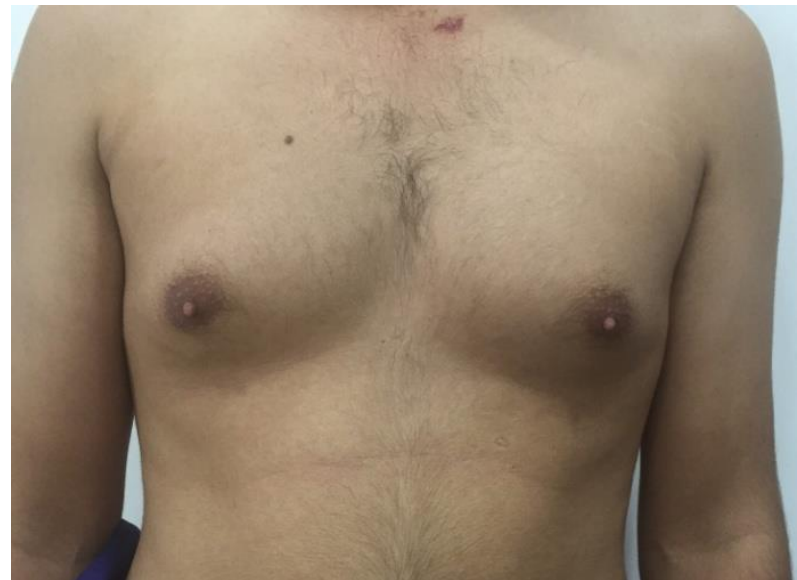

Figure 7(a)

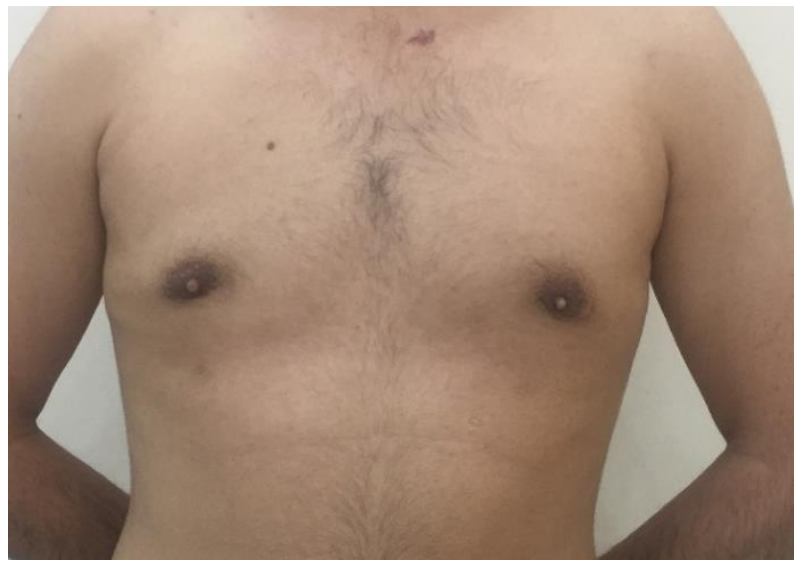

Figure $7(b)$

Figure 7 ( $a \& b)$ Patient with Simon 2a preoperative and post-operative result

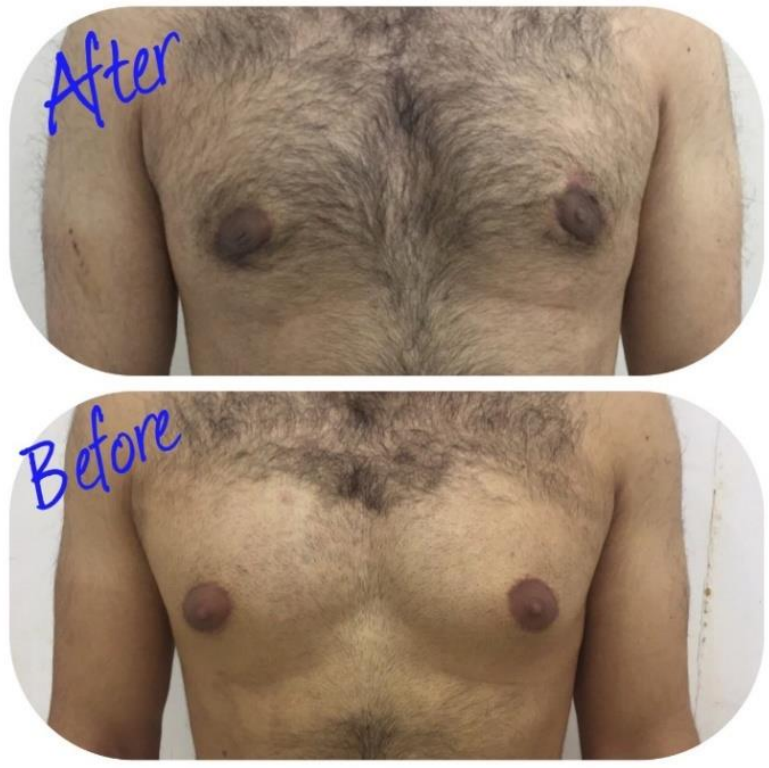

Figure 8 (a) Showing anteroir Simon 2B veiws befor and after operation

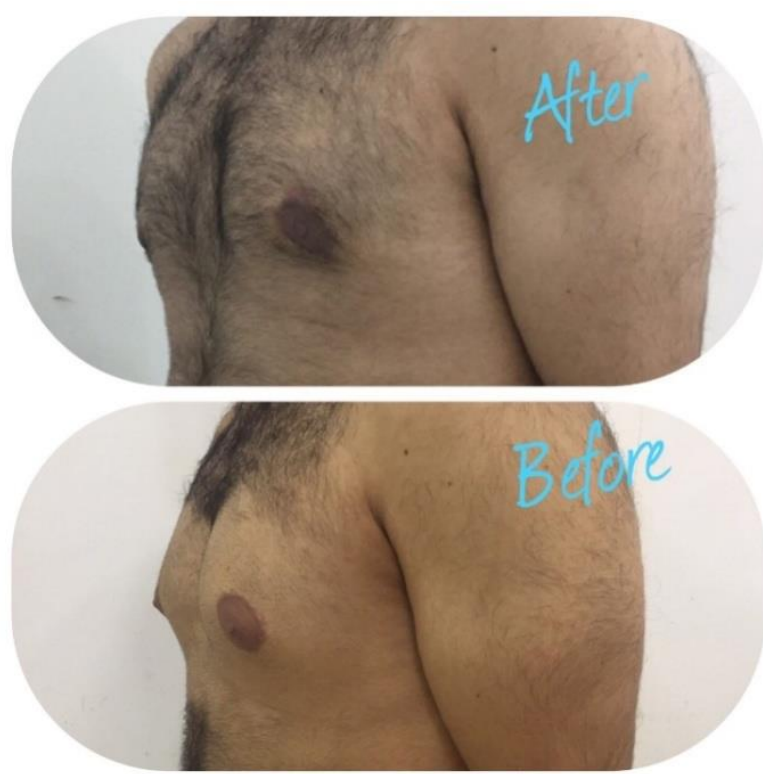

Figure 8 (b) Showing Simon 2B oblique view before and after
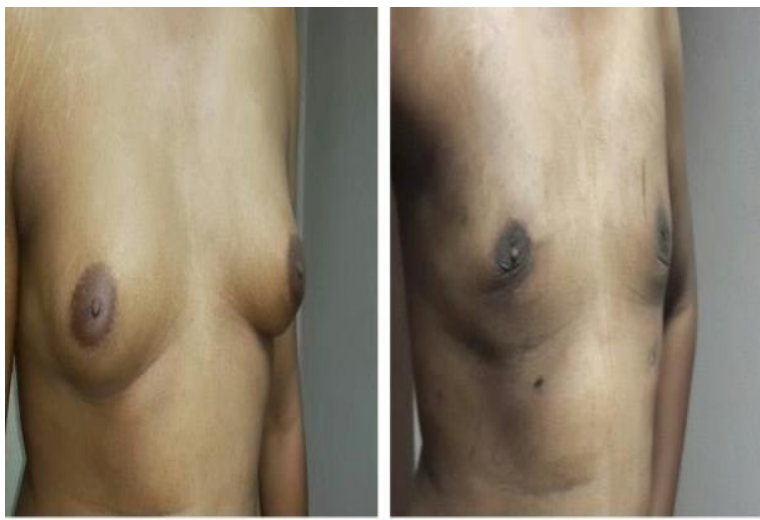

Figure 9 (a) Oblique view, patient with Simon 3 befor and after operative
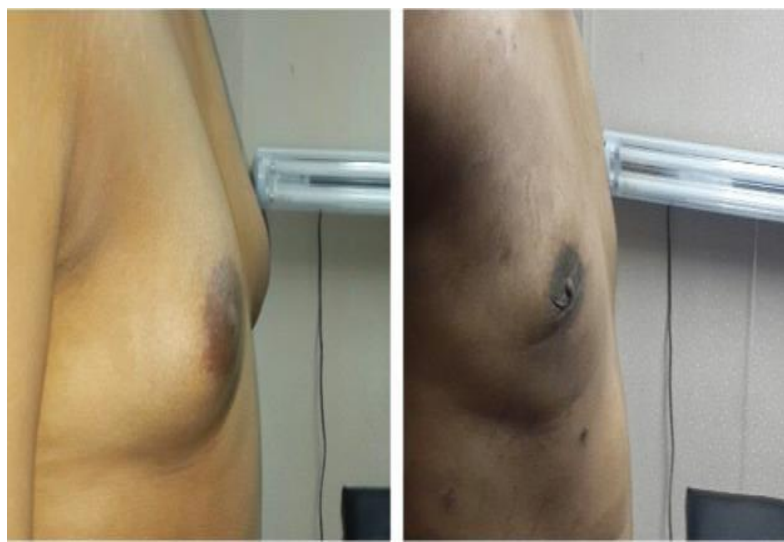

Figures (b) Lateral views with Simon 3 befor and after operative 


\section{Reference}

1- P. Gikas, K. Mokbel. Management of gynaecomastia: an update. Int $\mathrm{J}$ ClinPract, July 2007, 61, 7, 1209-1215

2- $\quad$ Lee, Bo Hyung ; Kwon, Yu Jin ; Park, Jang Wan Hwang, Jae $\mathrm{Ha}$; Kim, KwangSeog ; Lee, Sam Yong.Gynecomastia surgery is associated with improved nipple location in young korean patients. Archives of plastic surgery, November 2014, Vol.41(6), pp.748-52

3- Deepinder, Fnu ; Braunstein, Glenn D.Gynecomastia: incidence, causes and treatment. Expert Review of Endocrinology \& Metabolism, Sept, 2011, Vol.6(5), p.723.

4- Biro, F. M., Lucky, A. W., Huster, G. A., and Morrison, J. A. Hormonal studies and physical maturation in adolescent gynecomastia. J. Pediatr. 1990.116: p 450

5- Edmondson, H. A., Glass, S. J., and Soll, S. N. Gynecomastia associated with cirrhosis of the liver. Proc. Soc. Exp. Biol. Med,1939. 42: 97.

6- Rochefort, H., and Garcia, M. The estrogenic and antiestrogenic activities of androgens in female target tissues. Pharmacol. Ther. 1983.23: 193

7- Carlson HE. Approach to the patient with gynecomastia. J ClinEndocrinolMetab. 2011 Jan. 96(1):15-21.

8- Mahoney CP. Adolescent gynecomastia. Differential diagnosis and management. PediatrClin North Am. 1990 Dec. 37(6):1389-404.

9- Sophocles Lanitis , Elizabeth Starren , James Read , et al . Surgical management of Gynaecomastia. The Breast 17 (2008) 596-603.

10- Li, Chun-Chang ; Fu, Ju-Peng ; Chang, ShunCheng ; Chen, Tim-Mo ; Chen, Shyi-Gen. Surgical treatment of gynecomastia: complications and outcomes. Annals of plastic surgery, November 2012, Vol.69(5), pp.5105 .

11- Morselli, P. G. "Pull-through": A new technique for breast reduction in gynecomastia. Plast. Reconstr. Surg. 97: 450, 1996.

12- Bracaglia, R., Fortunato, R., Gentileschi, S., Seccia, A., and Farallo, E. Our experience with the so-called pull-through technique combined with liposuction for management of gynecomastia. Ann. Plast. Surg. 53: 22, 2004

13- Ramon, Y., Fodor, L., Peled, I. J., Eldor, L., Egozi, D., and Ullmann, Y. Multimodality gynecomastia repair by crosschest power-assisted superficial liposuction combined with endoscopic-assisted pullthrough excision. Ann. Plast. Surg. 55: 591, 2005.

14- Cristina S. McLaughlin at el. Displaced Epithelium After Liposuction for Gynecomastia. International Journal of Surgical Pathology 2016,19(4) 510-513.

15- Rohrich RJ, Beran SJ, Di Spaltro F, et al. Extending the role of liposuction in body contouring with ultrasound assisted liposuction. PlastReconstr Surg. 1998; 101:1090-1102.

16- Walgenbach KJ, Riabikhin AW, Galla TJ, et al. Effect of ultrasonic assisted lipectomy on breast tissue: histological findings. AesthPlast Surg.2001; 25:85-88

17- Hart, Alexandra M.; Duggal, Clarie; Pinell-White, Ximena. A Prospective Randomized Trial of the Efficacy of Fibrin Glue, Triamcinolone Acetonide, and Quilting Sutures in Seroma Prevention after LatissimusDorsi Breast Reconstruction. Plastic and Reconstructive Surgery. 139:854-863, April 2017.

18- Hurvitz, Keith A.; Olaya, Windy A.; Nguyen, Audrey. Evidence-Based Medicine: Abdominoplasty.Plastic and Reconstructive Surgery. 133:1214-1221, May 2014. 